pic fractionations occurring during evapotranspiration and cellulose synthesis can be modelled semiempirically to permit quantitative derivation of paleo-isotope values for local meteoric water (and hence paleotemperature) and paleohumidity.

This preliminary study utilizes stable isotope techniques to examine recent climate change in the Red River basin of southern Manitoba, Canada. At present, the regional tree-ring record extends from $A D$ 1999 to AD 1286. Isotopic data has been extracted from three trees from Winnipeg parks to generate an annual record of fluctuations in oxygen and carbon isotopes from 1802 to 1990 (see Figs. 1 and 2 below). These preliminary results suggest that the isotopic variations in the trees are closely linked to past variations in regional hydroclimate and growing season temperature.
Amalgamated oxygen and carbon isotopic values for the three tress (2 oak trees from Kildonan Park and one from St. Vital Park) are presented to illustrate departures from mean oxygen (Fig. 1) and carbon (Fig. 2) values.

In Figure1, negative oxygen-18 anomalies (indicating significantly depleted oxygen isotope values) are centred on the historical 1811, 1826, 1852 and 1861, 1896. Positive oxygen-18 anomalies correspond nicely with historical droughts (1803-1805; 1816-1820) and excessively dry periods (1840).

When compared with Winnipeg instrumental records, preliminary delta $\delta^{13} \mathrm{C}$ cellulose values portrayed as departures from a mean show a fairly positive relationship with recorded growing season temperature variations (average monthly daytime temperatures from June to September). Particularly noteworthy in Figure 2 is a period between 1874 and 1935 characterized by increasing growing season temperatures, which is positively mimicked by delta $\delta^{13} \mathrm{C}$ cellulose that change from below to above average values. Additionally, Figure 2 hints towards a particularly warm period during the middle of the $19^{\text {th }}$ century proceeded by a cold period that mimics the historical late $19^{\text {th }}$ century cold period. The initial results of this research indicate that oak cellulose oxygen isotope departures from a mean do provide historically reasonable chronological signatures of floods and droughts in the Red River basin. Additionally, carbon isotope results provide qualitative estimates of growing season temperature variations and therefore a climate framework in which to place these flood and drought anomalies.

\title{
A New Conceptual Model for Predicting Isotopic Enrichment of Lakes in Seasonal Climates
}

JoHN J. GIBSON

Department of Earth Sciences, University of Waterloo, Waterloo ON, Canada, N2L 3 G1 (Present address: International Atomic Energy Agency, Wagramerstrasse 5, P.O. Box. 100, Vienna, AUSTRIA) J.J.Gibson@iaea.org

Steady-state isotope balance models have often been applied to estimate long-term average water balance conditions for lakes (Dinçer, 1968; Gat, 1995). Such studies have commonly employed values for the kinetic isotope fractionations for oxygen and hydrogen determined from wind tunnel experiments (e.g. Vogt, 1976; see also Gonfiantini 1986) and have assumed isotopic equilibrium between atmospheric moisture and local mean annual precipitation (Rozanski et al., 2001; Gibson et al., 1993). In climates with a pronounced seasonality in evaporation rates, especially in environments where ice cover is present, such models have frequently predicted evaporative enrichment slopes that differ from observations (commonly lower than observed), and have therefore resulted in poor agreement between oxygen-18 and deuterium estimates, or have required use (or fitting) of kinetic frac- tionation factors that are not in agreement with experimental results (Zuber, 1983; Gibson et al., 1993).

A program of field investigations conducted at a variety of sites in northern Canada over the past decade has focused on development and application of quantitative isotope mass balance methods for water resources assessment in seasonal climates (see Gibson et al., 1994). These studies have included detailed comparisons of weekly to monthly evaporation in small, well-instrumented lakes using nonsteady isotope balance methods (Gibson et al., 1996a,b, 1998; Gibson 2002), regional comparisons of long-term water balance in boreal and arctic lakes (Gibson 2001; Gibson et al., 2002; Gibson and Edwards 2002), and application of evaporation pans and cryogenic vapour sampling to characterize isotopic composition of atmospheric moisture near the ground (Gibson et al., 1999). Overall, these studies have shown that application of isotope mass balance using pan-derived atmospheric moisture and laboratory values for kinetic exchange parameters yields consistent results for short time periods as compared to conventional water balance where evaporation is determined using Bowen ratio and aerodynamic profiling methods. Local and regional sampling surveys have also revealed a pronounced latitudinal steepening of the slope of local evaporation lines from about 5 to 7 in $\delta^{2} \mathrm{H}-\delta^{18} \mathrm{O}$ space over the latitude range of 50 to $71^{\circ} \mathrm{N}$.

A recent sensitivity analysis was conducted to investigate possible seasonality effects on the slope of the local evaporation lines that would explain the steeper slopes at higher latitudes, and the general lack of agreement between predicted evaporation slopes using 


\section{Science Highlights}

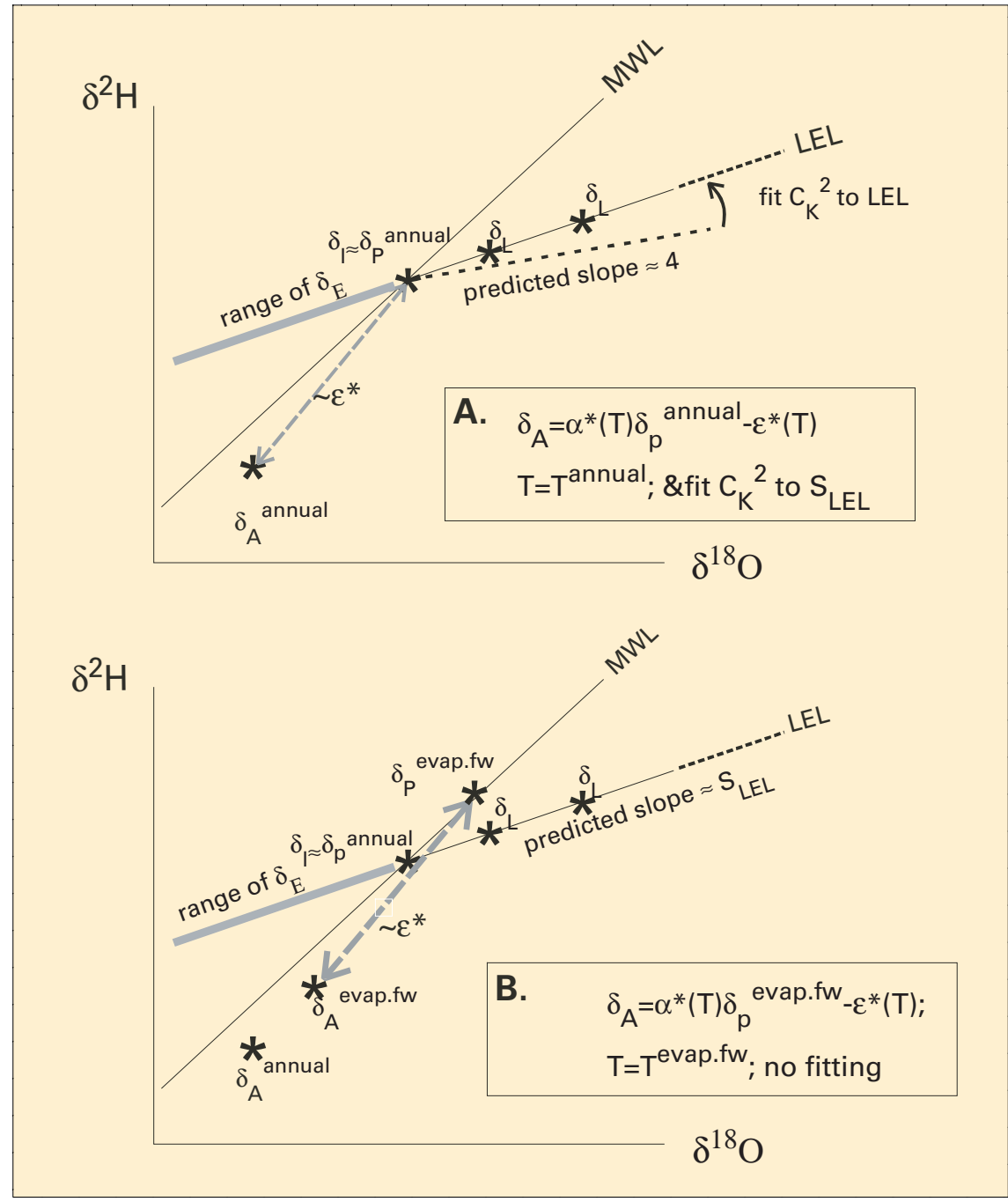

Fig. 1: Conceptual models showing the isotopic composition of major water balance components relative to the meteoric water line (MWL) and local evaporation line (LEL) in $\delta^{2} \mathrm{H}-\delta^{18} \mathrm{O}$ space: (a) original model assuming isotopic equilibrium between atmospheric moisture and precipitation (e.g. Gibson et al., 1993). Predicted slopes fall close to 4 and require fitting of the isotope exchange parameters to obtain good agreement between tracers; (b) refined model assuming equilibrium between flux-weighted precipitation and atmospheric moisture. Predicted slopes are close to the observed $L E L$ and do not require fitting of exchange parameters. $\delta_{P}$ is precipitation, $\delta_{A}$ is atmospheric moisture, $\delta_{E}$ is evaporating moisture, and $\delta_{\text {, are various }}$ lakewaters. $C_{K}{ }^{2}$ is the kinetic fractionation constant for deuterium, $\alpha^{*}(T)$ and $\varepsilon^{*}(T)$ are the respective equilibrium fractionation and separation factors for each isotope species, and $T$ is ambient temperature. Superscript "annual" and "evap. fw" denote mean annual and evaporation flux-weighted values.

the previously applied models. The analysis began by fitting atmospheric moisture $\left(\delta_{A}\right)$ so that predicted values of lake water $\left(\delta_{\mathrm{L}}\right)$ were constrained to fall on the local evaporation line. Notably, the resulting values of $\delta_{A}$ were also found to be very close to the values expected if weighted according to the evaporation flux, i.e., when $\delta_{A}$ is assumed to be in equilibrium with $\delta_{\mathrm{p}}$ but systematically filtered to account for the seasonality of the evaporation flux. Because the local evaporation line is a product of long-term evaporation from multiple lakes with differential throughflow, use of flux-weighted parameters is more realistic than use steepening of the local evaporation lines at higher latitudes and uses a consistent set of exchange parame- ters, as verified in the shorter-term field experiments. Lower slopes predicted by the original conceptual model are evidently due to improper (or lack of) weighting for the $\delta_{A}-\delta_{P}$ separation, which does not account for the absence of evaporation and isotope exchange during periods of ice-cover or for seasonal variability. An interesting point of particular relevance to paleoclimate studies is that temporal changes in seasonality may have altered the slope of the local evaporation in the past. Application of dual oxygen-18 and deuterium tracers to lake sediment archives may therefore be able to trace changes in slope of the local evaporation line, perhaps as a basis for examining changing seasonality. For modern water balance applications, the use of non-weighted atmospheric moisture values and standard exchange parameters can result in substantial errors in computed long-term values for evaporation-to-inflow ratios, particularly for strongly seasonal climates where errors may be as high as $50 \%$ for lakes having low throughflow and high evaporation. Another important implication is that the slopes of local evaporation lines should vary globally, with lower values at low latitudes and higher values at high latitudes and altitudes, which may be tested by spatial surveys of stable isotopes in surface waters.

\section{REFERENCES}

Dinçer, T., 1968: The use of oxygen-18 and deuterium concentrations in the water balance of lakes. Water Resources Research 4: 1289-1305.

Gat, J.R., 1995: Stable Isotopes of Fresh and Saline Lakes. In Physics and Chemistry of Lakes. Edited by A. Lerman, D. Imboden and J.Gat. Springer-Verlag, Berlin, 139-165

Gibson, J.J., 2002: Short-term evaporation and water budget comparisons in shallow arctic lakes using non-steady isotope mass balance Journal of Hydrology 264: 247-266.

Gibson, J.J. and Edwards, T.W.D., 2002: Regional surface water balance and evaporation-transpiration partitioning from a stable isotope survey of lakes in northern Canada. Global Biogeochemical Cycles 16: 25-38.

Gibson, J.J. Prepas, E.E. and McEachern, P., 2002: Quantitative comparison of lake throughflow, residency, and catchment runoff using stable isotopes: modelling and results from a survey of boreal lakes. Journal of Hydrology 262: 128-144.

For full references please consult:

www.pages-igbp.org/products/newsletters/ref2002_2.html 